ALFABETA: Jurnal Bahasa, Sastra, dan

Pembelajarannya

ISSN:2654-2587 (Print); ISSN:2654-735X (Online)

Volume IV, Nomor 1, Tahun 2021, Hal. $49-55$

Available online at:

http://ejurnal.budiutomomalang.ac.id/index.php/alfabeta

\title{
Research Article \\ TINDAK TUTUR DALAM TUTURAN LARA PANGKON MASYARAKAT NGANTANG
}

\author{
Adi $^{1}$, Trisnian Ifianti ${ }^{2}$ \\ IKIP Budi Utomo, Malang, \\ adi.doank.007.ad@gmail.com ${ }^{1}$ nianitubungas15@gmail.com²
}

\begin{abstract}
Informasi Artikel
Submit: $15-4-2021$

Diterima: $20-4-2021$

Dipublikasikan: $24-4-2021$

Analyzing the speech of Lara Pangkon in Ngantang this study aims to determine the forms of speech acts, explain its meaning and how the delivery of this speech. By using descriptive qualitative research methods, and narrative in Lara Pangkon as a primary source as well as the book the documentation as the source of secondary data. Acquisition of data through observation, interview, check out the note, and documentation. Data processing techniques are as follows: (1) a transcript and translation of the data, (2) the classification of the data, (3) data analysis, and (4) the exposure of the conclusion of the study. The end result of this research is there are 2(two) speech acts expressive, 2(two) said follow the directive, 2( two) speech acts assertive and 2( two) speech acts komisif are delivered with obvious can be delivered in a concise and straightforward and each speech act are said illocutionary.

Key words: speech act, Lara Pangkon, Ngantangness

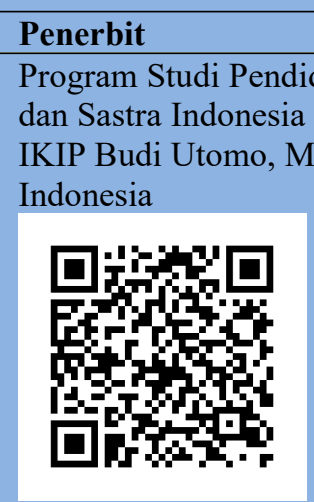

Tidak hanya menganalisa tuturan Lara Pangkon yang sering dilakukan masyarakat Kec. Ngantang penelitian ini juga bertujuan untuk mengetahui bentuk- bentuk tindak tutur, menjelaskan maknanya dan bagaimana penyampaian nya. Dengan menggunakan metode penelitian deskriptif kualitatif, dan tuturan dalam Lara Pangkon sebagai sumber primer serta buku dokumentasi sebagai sumber data sekunder. Pemerolehan data melalui observasi, wawancara, simak catat, dan dokumentasi. Teknik pengolahan data adalah sebagai berikut: (1) transkrip dan penerjemahan data, (2) klasifikasi data, (3) analisis data, dan (4) pemaparan kesimpulan hasil penelitian. Hasil akhirnya penelitian ini adalah terdapat 2(dua) tindak tutur ekspresif, 2(dua) tindak tutur direktif, 2( dua) tindak tutur asertif dan 2( dua) tindak tutur komisif yang disampaikan dengan jelas dapat disampaikan secara ringkas dan lugas dan masing masing merupakan tindak tutur ilokusi.
\end{abstract}

Kata kunci: tindak tutur, lara pangkon, masyarakat ngantang 


\section{PENDAHULUAN}

Budaya adalah suatu tatanan hidup yang dinamis, berkembang dan dimiliki bersama oleh sebuah masyarakat dan merupakan warisan dari generasi ke generasi. Walaupun kadang budaya juga dipengaruhi oleh letak geografis suatu masyarakat tetapi keberadaan budaya dalam masyarakat tersebut merupakan ciri khas daerah tersebut. Pada komunitas tradisional kegiatan kebudayaan merupakan salah satu wujud nyata dari pewarisan tradisi kebudayaan itu sendiri. Hal dapat dilihat dalam pelaksanaan upacara adatl, misalnya upacara kematian, kelahiran, perkawinan, sunatan, syukuran dan lain sebagainya yang mana budaya bisa menjadi sarana aktifitas sosial bagi suatu masyarakat. Tidak hanya sebagai usaha pengaktifan budaya dalam rangka melestarikan budaya, tetapi juga sebagai sarana interaksi sosial yang tidak akan lepas dari interaksi lingual.

Masyarakat kecamatan Ngantang adalah suku Jawa yang menempati Malang bagian barat dekat dengan wilayah Kediri dan Jombang. Hal ini memberikan pengaruh beberapa unsur budaya yang menjadi ciri-ciri kehidupan masyarakat Ngantang dengan kata lain dalam beberapa hal yang berkaitan dengan budaya, mereka memiliki kemiripan dan hal ini bisa di ketahui dari sumber-sumber tertulis, lisan dan gerak.

Salah satu unsur budaya yg paling primer merupakan bahasa. Namun pada hal ini, bahasa tidaklah ditinjau sebagaimana linguistik umum meninjaunya, melainkan ditinjau dari alat komunikasi antar masyarakat. Setiap aktivitas budaya pada suatu masyarakat tidak terlepas berdasarkan penggunaan bahasa (Suandi, 2014: 9). Pada upacara pernikahan misalnya, bahasa memegang peranan mulai berdasarkan awal upacara akad nikah hingga upacara temu manten. Salah satunya adalah Lara Pangkon dalam upacara temu manten yang masih banyak di ltemui di Ngantang. Lara Pangkon merupakan serangkaian acara yg bawakan sang pihak penganten laki- laki yg diwakili sang Pamasrah yg membawa Jagoan menjadi simbol berdasarkan pengantin laki- laki dan melakukan pencarian buat mendapatkan pengantin perempuan, tuturan yg masih ada pada Lara Pangon berisikan simbol- simbol bermakna yang menjadi nasehat bagi kedua penganten untuk mengarungi rumah tangga.

Studi tentang bahasa sebagai aktivitas komunitas atau studi tentang hubungan antara bahasa dan komunitas penggunanya disebut sosiolinguistik. Dalam proses komunikasi, individu atau komunitas yang menggunakan bahasa memiliki cara sendiri-sendiri dalam mengungkapkan ide, pikiran, dan perasaannya. Hubungan atau hubungan antar orang akan memilih bahasa tertentu berdasarkan kesepakatan bersama, sehingga tujuan komunikasi dapat tercapai. Hubungan komunikasi meliputi hubungan antar komunitas yang menggunakan bahasa itu sendiri . Masyarakat linguistik adalah sekelompok orang yang menggunakan bahasa yang sama untuk merasakan atau memikirkan diri sendiri. Pengalaman praktis membuktikan bahwa bahasa yang digunakan selalu muncul dalam bentuk tindak tutur tunggal atau majemuk. Kegiatan tuturan tidak hanya terbatas pada berbicara beberapa kata saja, tetapi juga melakukan sesuatu berdasarkan tuturan tersebut (Austin, Rusminto, 2010: 22). Hal ini juga didukung oleh Searle (Rusminto, 2010: 22) Pernyataan tersebut menunjukkan bahwa unit komunikasi terkecil bukanlah kalimat, tetapi perilaku tertentu, seperti membuat pernyataan, mengajukan pertanyaan, dan meminta.

Searle (dalam Leech, 2011: 166) juga membagi tindak tutur ilokusi dalam lima kategori, yaitu, asertif, direktif, komisif, ekspresif, dan deklaratif. Dalam penelitian ini tindak tutur yang diakaji adalah tindak tutur ilokusi. Tuturan dalam Lara Pangkon merupakan dialog yang disampaikan pihak keluarga pengantin laki- laki (di wakili oleh Pamasrah) dan di sambut oleh pihak keluarga pengantin perempuan( diwakili oleh Panampi). Proses ini akan menceritakan tentang pencarian pasangan oleh pengantin laki- laki yang di simbolkan ayam jago dari awal hingga akhir nya mendapatkan pasangan yang di maksud. Ujaran atau tuturan yang terdapat dalam Lara Pangkon diteliti berdasarkan teori pragmatis, karena tuturan yang 
disampaikan oleh Pamasrah dan Panampi selaku wakil keluarga dalam upacara adat yang dilaksanakan di masyarakat Ngantang merupakan salah satu bentuk tingkah laku tuturan, alasannya adalah karena bahasa dalam bahasa tersebut berinteraksi dengan proses upacara adat. Levinson (1993: 48) mendefinisikan pragmatik sebagai studi bahasa, yang bertujuan untuk mempelajari hubungan antara konteks dan konteks dalam tuturan lisan. Sementara Parker (dalam Rahardi, 1986: 48) pragmatik adalah ilmu yang mempelajari struktur bahasa dari luar. Dari isi yang diungkapkan oleh kedua angka tersebut, dapat disimpulkan bahwa praktik merupakan suatu kajian yang berperan penting dalam menganalisis dan memperoleh makna bahasa dalam konteksnya. Pragmatik mengkaji bahasa untuk memahami maksud penutur dengan mempertimbangkan konteksnya. Penelitian pragmatis absolut harus berkaitan erat dengan konteks tuturan, yang sejalan dengan teori Leech (1993: 8) yang menyatakan bahwa "pragmatik adalah studi tentang makna dan hubungannya dengan konteks tuturan". Menurutnya, pragmatik mengkaji bagaimana bahasa memahami maknanya dalam interaksi, sedangkan pragmatik juga mengkaji makna dalam konteks, bukan makna abstrak. Dari pengertian di atas dapat disimpulkan bahwa pragmatik merupakan ilmu kebahasaan yang mempelajari penggunaan bahasa yang ditentukan oleh adanya konteks bahasa dalam masyarakat dan faktor budaya yang menjadi wadah dan latar belakangnya. Apa yang pembicara katakan dapat dipahami oleh pembicara. Hal tersebut yang mendasari peneliti dalam mengkaji tindak tutur dalam tuturan Lara Pangkon yang dilakukan masyarakat Ngantang guna mengetahui tindak tutur apa saja yang ada dalam tuturan tersebut serta arti apa yang tercantum di dalam tuturan Lara Pangkon tersebut selaku upaya pemertahanan budaya Lara Pangkon warga Ngantang.

\section{METODE PENELITIAN}

Riset ini dilaksanakan di Desa Jombok Kec. Ngantang Kab. Malang. Dimana di tempat tersebut warga masih mengadakan kegiatan Lara Pangkon dalam upacara temu manten. Sesuatu riset pasti saja memerlukan informasi ialah keseluruahan datayang dijadikan bahan riset. Sebab riset ini bertujuan mendapatakan beberapa informasi yang berupa lisan, hingga yang jadi sumber informasi merupakan hasil wawancara dengan tetua adat dalam perihal ini merupakan pelakon Lara Pangkon warga kecamatan Ngantang. Metode yang digunakan adalah desktiptif kualitatif, dimana tata cara ini menjelaskan sesuatu kondisi yang sesuai kondisi sesungguhnya. Metode kualitatif sangat sesuai digunakan buat meningkatkan teori yang dibentuk lewat informasi yang diperoleh dari lapangan( Sugiyono, 2005: 23). Pengumpulan data dilakukan dengan cara: (1) Melakukan observasi, yaitu dengan melakukan pendokumentasian atau merekam tuturan pada objek yang dikaji. Data akan diperoleh dari rekam simak prosesi Lara Pangkon dalam upacara temu manten. (2) Teknik interview, yaitu dengan melakukan wawancara kepada informan yaitu tokoh masyarakat/ tetua pelaku Lara Pangkon, dimana interview yang dilakukan secara tidak terstruktur yaitu pertanyaan tidak ditentukan/dibatasi sebelumnya, sehingga peneliti memberikan kebebasan kepada informan untuk menjawab atas setiap pertanyaan yang dikaji. Sehinga dapat diperoleh jawaban atas informasi bagaiamana tuturan Lara Pangkon dalam upacara tersebut. Metode analisis informasi dalam riset ini dengan metode dokumentasi serta analisis informasi mengenali informasi sederhanal sehingga lebih mudah di kaji maknanya. Informasi yang terkumpul dari hasil rekaman ataupun hasil wawancara lapangan diarsipkan kemudian ditranskripkan ke wujud tulisan serta yang diterjemahkan ke dalam bahasa Indonesia guna memudahkan analisa, mengklasifikasi tindak tutur serta menganalisis arti ataupun wujud tindak tutur setelah itu merumuskan hasil riset sehingga permasalahan terjawab. 


\section{HASIL DAN PEMBAHASAN}

Sumber informasi hasil rekam catat akan diklasifikasi, setelah itu dilanjutkan dengan merubah rekaman serta hasil wawancara kedalam wujud tulisan serta diterjemahkan ke bahasa Indonesia. Informasi tersebut setelah itu diklasifikasikan serta dianalisa ataupun dirangkum selaku hasil riset. Informasi yang dianalisa peneliti adalah bagian dari tuturan Lara Pangkon yang mana terdapat 2 bagian, Pambuka serta Paneges. Dari hasil analisis informasi yang didapat bisa dipaparkan wujud/ jenis serta makna tindak tutur. Bagian Pambuka dalam Lara Pangkon adalah bagian pengenalan. Pada bagian ini Pamasrah selaku wakil dari pihak pengantin perempuan mendatang rumah pihak pegantin perempuan yang di yakini sebagai pasangan dari pengantin laki- laki. Pamasrah dengan membawa ayam jago terbuat dari kayu sebagai simbol dari penganting laki- laki diikuti banyak oarang sebagai pengiring. Pada bagian ini tutran nya berisikan perkenalan dan penjelasan keberadaan si Jago( simbol penganti laki- laki). Pada bagian Paneges, dimana pada bagia ini adalah Panmpi selaku wakil dari pihatk pengantin permpuan menerima / menegaskan bahwa pihak keluarga pengantin perempuan menginginkan si jago/ pengantin laki- laki. Tuturan ini disampaikan dalam posesi Lra Pangkon ini adalah tuturan penuh makna sebagai nasehat bagi kedua pengantin dalam mengarungi rumah tangga. Menurut Nadar (2013: 14), perilaku tutur adalah apa yang ingin dicapai pembicara ketika berbicara, bisa berupa janji, permintaan maaf, ancaman, prediksi, perintah, permintaan, dll. Tindak tutur ilokusi dapat dikatakan sebagai perilaku terpenting dalam mempelajari dan memahami tindak tutur.

Berikut data tuturan yang ditemukan dan kemudian dianalisa dari tuturan Lara Pangkon yang telah teridentifikasi sebagai tindak tutur ilokusi.

Data 1

Pamasrah:“Kula saking Suroloyo Adilinuwih. Suro tegese
wani, loyo pati, adi bagus, linuwih samubarang
kalire. Lajeng panjenengan meniko sinten, lan
niki dusun pundi?"
Panampi : "Nami kulo Darmojulig. Darmo niku temen, Julig
niku duta perwakilan, lan niki dusun Karang
Kadempel. Tebih saking Suroloyo dumugi
Karang Kadempel mriki, menopo ingkang
sampeyan padosi, Dhik?"."

Tuturan diatas juga menunjukkan bagaimana pemakaian tuturan ekspresif yang di ucapkan dengan hormat. Pada bagian Pambuka ini,bisanya di ucapkan salam dan perkenalan. Dalam hal ini pihak keluarga pengantin perempuan yang di wakili oleh Panampi menayakan perihal kedatang pihak keluarga penganti laki- laki yang di wakili oleh Pamasrah dengan rombongan pengiring nya membawa jago sebagai simbol pengantin lakilaki. Pada data diatas tampak bahwa tindak tutur ekspresif mengenalkan diri sebagai bentuk penghormatan.

Data 2

Panampi : "Lha ingkang sampeyan beto niku napa, Dhik?"

Pamasrah: "Niki Sawung Seto Wono. Tegese, sawung jago, seto putih, wono alas." 
Tuturan diatas juga menunjukkan bagaimana pemakaian tuturan ekpresif yang di ucapkan bertujuan untuk mengenalkan kedatangan dari pihak pengantin laki- laki. Pada kalimat "Niki Sawung Seto Wono. Tegese, sawung jago, seto putih, wono alas" memiliki arti " Ini jago putih dari hutan", atau bermakna ayam jago/pengantin laki- laki adalah masih putih atau polos.atau lugu Dalam konteks ini dimaksudkan bahwa kedatang pihak pengantin laki- laki yang disimbolak dengan ayam jago adalah masih polos/lugu, belum pernah berkeluarga, masih bujangan.dan sedang mencari pasangan. Pemakaian tuturan asertif yang tepat tersebut menyatakan bahawa pihak Pamasrah/pengantin laki- laki menyatakan diri sebagai seorang laki- laki yang mencari pasangan nya..

Data 3

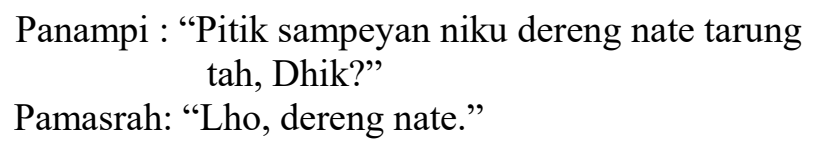

Tuturan diatas adalah tuturan kategori komisif yang merupakan pernyataan menjanjikan atau menjamin. Pada kalimat "lho dereng nate" , memiliki arti bahwa belum pernah si jago/ pengantin laki- laki bertarung. Dalam konteks ini tuturan komisif telah di ungkapkan yaitu menjajikan jaminan bahwa memang si jago/ pengantin laki- laki belum pernah bertarung yang memiliki makna berkeluarga.

Data 4

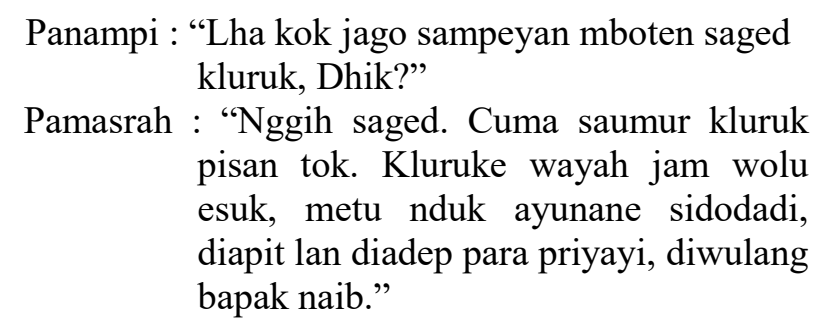

Tuturan diatas adalah tuturan dengan kategori komisif, menjanjikan Pamasrah karena Panampi meragukan jawaban tersebut. Kata "Nggih saged................", artinya "tentu saja bisa", adalah tuturan komisif yang menunjukkan jaminan/ menjajikan bahwa bisa untuk melakukan sesuatu di masa mendatang dalam hal ini yang menuturkan adalah Pamasrah.

Data 5

$$
\begin{gathered}
\text { Pamasrah : "Lho empun ndeder perkoro lho, nggih? } \\
\text { Pengin ngepek jago kulo, kulo } \\
\text { rewangi pecahe jojo wutahe ludiro." } \\
\text { Panampi : "Lho nek ngaten ayo, Dhik." }
\end{gathered}
$$

Data di atas merupakan bentuk tuturan kategori asertif dengan maksud menerima semua penjelasan dari Pamasrah. Setelah dijelaskan semua unsur- unsur kebaikan yang ada dalam si jago( simbol pengantin laki- laki), Panampi merasa jelas atas apa yang dijelaskan sehingga menyetujui apa yg disyaratkan oleh Pamasrah, di tunjukakn pada kalimat" Lho nek ngaten ayo, Dhik."memiliki makna "Biklah kalau begitu”. Sehingga untik mengkiritisi itu di ungkapkan dengan tuturan ekspresif sebagai isyrat memahami penjelasan Pamasrah .

Data 6

Pamasrah: "Nggih niki jagone kulo 


\author{
sukakaken sampeyan, tapi \\ mboten gampang kula \\ sukakaken lho. Wonten tebusane." \\ Panampi : "Lha nopo tebusane?"
}

Tuturan dia tas berarti pujian yang di lontarkan oleh Pamasrah kepada si jago( simbol pengantin laki- laki). Tuturan ini masuk dalam kategori direktif yaitu menyampaikan permintaan. Kalimat " Nggih niki jagone kulo sukakaken sampeyan, tapi mboten gampang kula sukakaken lho. Wonten tebusane" memiliki arti bahawa jika ingin memiliki jago tersebut ada yang harus di tebus sebagai syarat. Sehingga di pilihlah kalimat yang tepat untuk menyampaikan persyaratan tersebut.

Data 7

Pamasrah : "Sampun kulo jelentrehaken sedoyo.

Sakniki kulo titip jago niki minongko anak kulo

lanang."

Panampi : "Nggih, Dhik, kula tramine sampeyan

sekseni."

Tuturan dia atas artinya adalah penerimaan. Ketika Panampi ingin meminta si jago (pengantin laki- laki) untuk di pelihara (diambil menantu), Pamasrah dengan halus menerima. Tuturan ini msuk dalam kategori asertif yaitu pernyataan penerimaan Kata "Nggih, Dhik, kula tramine sampeyan sekseni.", merupakan penerimaan dari segala penjelasan Pamasrah.

Data 8

$\begin{aligned} & \text { Panampi : "Napa mawon isine?" } \\ & \text { Pamasrah : } \text { "Gedang minongko sajen, tegese } \\ & \text { gegedo lan padango pikire, } \\ & \text { ngajenono awake. Kupat lepet } \\ & \text { ngluwaro nadare, ngluwarono } \\ & \text { sengkalane, netepano agamane, } \\ & \text { cedakno rejekine, adohno bilahine." }\end{aligned}$

Tuturan " cedakno rejekine, adohno bilahine" memiliki arti " dekatkan rejekinya, jauhkan halangan nya", makna kalimat ini adalah permohonan atau doa agar dalam mengarungi rumah tangga kedua pengantin senantiasa didekatkan rejekinya dan dijauhkan halangan nya dan kalimat tersebut masuk dalam kategori direktif .

\title{
KESIMPULAN
}

Tuturan yang yang di sampaiakan dalam Lara Pangkon seperti yang telah paparkan pada latar belakang masalah, tutran dialog nya dilakukan oleh Pamasrah dan Panampi yang maknanya memilik tujuan memberikan gambaran perjalanan kedua pengantin dalam mengarungi rumah tangga. Dari observasi dan interview, data yang di peroleh dianalisis, dan merupakan tuturan yang telah diklasifikasikan sesuai kategori dari tuturan. Dari hasil penelitian yang telah dilakukan maka ditemukan bahwa: (1) Tindak tutur salam memperkenalkan diri, merupakan tuturan klasifikasi tindak ilokusi dengan kategori tuturan ekspresif. (2)Tindak tutur meminta, memohonkan doa- doa / harapan merupakan tuturan kalisifikasi tindak ilokusi dengan kategori tuturan direktif. (3) Tindak tutur penerimaan merupakan pernyataan tindak ilokusi dengan kategori tuturan asertif. (4) Tindak tutur 
meminta penjelasan merupakan tuturan klasifikasi ilokusi degan penyampaiannya dengan tuturan kategori direktif. (5). Tindak tutur menjaminkan/ menjajikan merupakan tuturan dengan klasifiaksi ilokusi komisif.

\section{RUJUKAN}

Hamid Hasan Lubis, H.A. 1991. Analisis Wacana Pragmatik. Bandung, Angkasa.

Levinson, Stephen C. 1993. Pragmatics. Cambridge : Cambridge University Press.

Leech, Geoffry. 1993. Prinsip-Prinsip Pragmatik. Jakarta. Universitas Indonesia.

Leech, Geoffrey. 2011. Prinsip-Prinsip Pragmatik. (edisi terjemahan M.D.D Oka) Jakarta: Universitas Indonesia Press.

Nader, F.X. 2008. Pragmatik dan Penelitian Pragmatik. Yogyakarta. Graha Ilmu.

Nadar, F.X. 2013. Pragmatik \&Penelitian Pragmatik. Yogyakarta: Graha Ilmu.

Rahardi, Kunjana. 2005. Pragmatik Kesantunan Imperatif Bahasa Indonesia.

Yogyakarta: Erlangga.

Rusminto, Nurlaksana Eko. 2010. Memahami Bahasa Anak-anak: Sebuah Kajian Analisis Wacana Panduan Bagi Guru, Orangtua, dan Mahasiswa Jurusan Bahasa. Bandar Lampung: Universitas Lampung.

Sugiyono. 2005. Memahami Penelitian Kualitatif. Bandung: Penerbit CV Alfabeta.

Suandi, I Nengah.2014. Sosiolinguistik. Yogyakarta: Graha Ilmu. 